\section{Charge Transer Exciplex Emission Involving a Transi- tion Metal Complex}

\section{A. VOGLER* and H. KUNKELY}

Universität Regensburg, Institut für Chemie, D-8400 Regensburg, F.R.G.

Received July 24,1980

Exciplex formation and emission of organic compounds has been investigated extensively $[1,2]$. Charge transfer (CT) as well as excitation resonance can contribute to the stability of exciplexes. CT exciplexes may play an important role in biomolecular electron transfer reactions of electronically excited molecules. Although there is an increasing interest in these reactions involving transition metal complexes [3, 4], very little is known about exciplexes of coordination compounds [5]. Nonemitting exciplexes between metalloporphyrins and organic molecules were detected, but the extent of CT contribution is not clear $[4,6]$. We describe here the formation of an emitting CT exciplex between $\operatorname{Re}\left(4,7\right.$-diphenyl-1,10-phenanthroline)(CO) ${ }_{3}$ $\mathrm{Cl}(\mathrm{I})$ as electron acceptor and $\mathrm{N}, \mathrm{N}$-dimethylaniline (DMA) as electron donor.

Complexes of the type $\operatorname{Re}(\mathrm{L}-\mathrm{L})(\mathrm{CO})_{3} \mathrm{Cl}(\mathrm{L}-\mathrm{L}=$ $o$-phen and related ligands) are well suited for our study because they emit a strong luminescence in solution at room temperature [7]. In contrast to $\left[\mathrm{Ru}(\mathrm{bipyr})_{3}\right]^{2+}$ the complex 1 dissolves also in nonpolar solvents as alkanes which are necessary for the observation of an emission from CT exciplexes [1, 2]. The emission of $\operatorname{Re}(\mathrm{L}-\mathrm{L})(\mathrm{CO})_{3} \mathrm{Cl}$ comps from an intramolecular ( $\operatorname{Re}$ to $\mathrm{L}-\mathrm{L}$ ) $\mathrm{CT}$ triplet [7]. The ground state complexes can be oxidized and reduced at relatively low potentials $\left(\mathrm{E}_{1 / 2} \sim+1.3\right.$ and $\sim-1.3 \mathrm{~V}$ vs. SCE) [8]. In acetonitrile the excited complexes were shown to be quenchable with organic electron donors and acceptors. The quenching constants correlate well with the redox potentials of the complexes and the organic quenchers. The electron transfer is reversible since there is no net chemical reaction [8]. The quenching constant $\left(\sim 10^{9} \mathrm{~mol}^{-1} \mathrm{~s}^{-1}\right)$ for DMA $\left(\mathrm{E}_{1 / 2}=+0.78 \mathrm{~V}\right.$ vs. SCE) seems to be near the diffusion-controlled limit.

Upon addition of DMA to a solution of 1 in decaline or isooctane the absorption spectrum of 1 does not change at low DMA concentrations $\sim 10^{-2} M$. The orange emission $\left(\lambda_{\max }=575 \mathrm{~nm}\right)$ of 1 dissolved in alkanes is not quenched by DMA but converted

*Author to whom correspondence should be addressed.

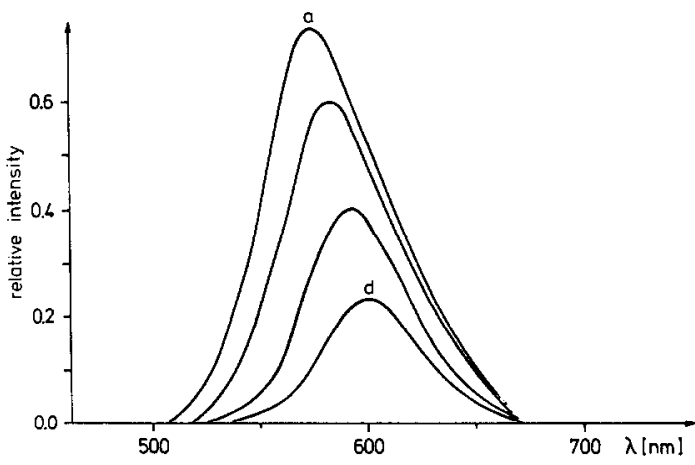

Fig. 1. Emission spectra of $1.5 \times 10^{-4} M \operatorname{Re}(4,7-$ diphenyl1,10-phenanthroline)(CO) ${ }_{3} \mathrm{Cl}$ in decaline in the presence of a) $0 \mathrm{M}$, b) $8 \times 10^{-4} \mathrm{M}$, c) $2 \times 10^{-3} \mathrm{M}$, d) $8 \times 10^{-3} \mathrm{M}$ $\mathrm{N}, \mathrm{N}$-dimethylaniline.

to a new, less intense red emission $\left(\lambda_{\max }=600 \mathrm{~nm}\right)$. This conversion was almost complete at $8 \times 10^{-3}$ $M$ DMA (Fig. 1). A further increase of the concentration of DMA did not affect the red emission. At the exciting wavelength $(405 \mathrm{~nm})$ the light was only absorbed by 1 but not by DMA. On the contrary, the wavelength of emission of 1 dissolved in acetonitrile was not changed by DMA but the emission was simply quenched obeying a Stern-Volmer kinetics as it was observed before [8]. At $8 \times 10^{-3} M$ DMA the emission of 1 was not anymore detectable.

These results suggest that the new emission of $l$ at $600 \mathrm{~nm}$ in alkanes in the presence of DMA is due to the formation of a CT exciplex.

$$
\begin{aligned}
& 1^{*}+\mathrm{DMA}^{\rightarrow}\left(1^{-} \mathrm{DMA}^{+}\right)^{*} \\
& \left(1^{-} \mathrm{DMA}^{+}\right)^{*} \stackrel{\text { alkane }}{\longrightarrow} 1+\mathrm{DMA}+\text { emission }
\end{aligned}
$$

The emission of exciplexes, stabilized by excitation resonance, is hardly affected by solvents $[1,2]$. But in agreement with our observation the emission of CT exciplexes is quenched in polar solvents due to the dissociation into ions $[1,2]$ :

$$
\left(1^{-} \mathrm{DMA}^{+}\right)^{*} \stackrel{\mathrm{CH}_{3} \mathrm{CN}}{\longrightarrow} 1^{-}+\mathrm{DMA}^{+}
$$

The emission intensity of the exciplex in decaline decreased while that of $I$ increased with increasing temperature. From the temperature dependence (between $20^{\circ}$ and $180^{\circ} \mathrm{C}$ ) of the ratio of the emission intensity of 1 to that of the exciplex $[9,10]$ we determined the enthalpy of exciplex formation $\Delta \mathrm{H}=-5.7 \mathrm{kcal} \mathrm{mol}^{-1}$. From this enthalpy and the energy of the emitting state of 1 the energy of the CT exciplex can be obtained $[10,11]$. Although the triplet energy of 1 is not known (spectroscopic 0,0 transition) it has been estimated to be $N 2.3 \mathrm{eV}$ 
(53 kcal) above the ground state [8]. The energy of the CT exciplex $\mathrm{E}\left(1^{-} \mathrm{DMA}^{+}\right) \sim 48 \mathrm{kcal}$ does not agree very well with that $(51 \mathrm{kcal})$ calculated by Weller's empirical equation $[10,11]$ using the redox potentials of DMA and 1. But there is quite some uncertainty in the values used in these calculations. In addition, Weller's equation was derived from organic compounds and may not apply strictly to transition metal complexes. From the energy of the CT exciplex and the energy of the exciplex emission band at its maximum the ground state repulsion can be obtained. The calculation shows that there is little if any ground state repulsion.

Besides DMA other amines were found to form also emitting exciplexes with 1 in alkanes. However, with electron acceptors as quinones and 1,4-dicyanobenzene we did not observe exciplex emission. It is possible that the geometry of 1 prevents the appropriate approach of these molecules, while it is well known that amines do not have strong geometrical preferences for exciplex formation $[12,13]$.

\section{Acknowledgements}

Financial support for this research by the Deutsche Forschungsgemeinschaft and the Fonds der Chemischen Industrie is gratefully acknowledged.

\section{References}

$1 \mathrm{H}$. Beens and A. Weller, in Organic Molecular Photophysics, Vol. 2 (J. B. Birks, Ed.) Wiley, New York, 1975. 2 B. Stevens, Adv. Photochem., 8, 161 (1971).

3 V. Balzani, F. Bolletta, M. T. Gandolfi, and M. Maestri, Topics in Current Chemistry, 75, 1 (1978).

4 D. G. Whitten, Acc. Chem. Res., 13, 83 (1980).

5 An emitting exciplex between $\operatorname{Ir}(o \text {-phen })_{2} \mathrm{Cl}_{2}^{+}$and naphthalene was reported by R. Ballardini, G. Varani, L. Moggi, and V. Balzani, J. Am. Chem. Soc., 96, 7123 (1974), hut later corrected to be due to an impurity, J. Am. Chem. Soc., 99, 681 (1977).

6 J. K. Roy, F. A. Carroll, and D. G. Whitten, J. Am. Chem. Soc., 96, 6349 (1974).

7 M. Wrighton and D. L. Morse, J. Am. Chem. Soc., 96, 998 (1974).

8 J. C. Luong, L. Nadjo, and M. S.Wrighton, J. Am. Chem. Soc., 100, 5790 (1978).

9 B. Stevens and M. I. Ban, Trans. Faraday Soc., 60, 1515 (1964).

10 H. Knibbe, D. Rehm, and A. Weller, Ber. Bunsenges. Physik. Chem., 73, 839 (1969).

11 D. Rehm and A. Weller, Z. Phys. Chem., N.F., 69, 183 (1970).

12 E. A. Chandross and H. T. Thomas, Chem. Phys. Lett., 9, 393 (1971).

13 G. N. Taylor, E. A. Chandross, and A. H. Schiebel, J. Am. Chem. Soc., 96, 2693 (1974). 